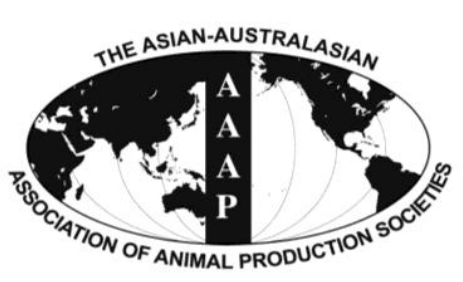

\begin{tabular}{c} 
Open Access \\
Asian Australas. J. Anim. Sci. \\
Vol. 28, No. 8 : 1061-1065 August 2015 \\
http://dx.doi.org/10.5713/ajas.14.0783 \\
\hline www.ajas.info \\
pISSN 101 1-2367 elSSN 1976-5517
\end{tabular}

\title{
Estimation of Genetic Associations between Production and Meat Quality Traits in Duroc Pigs
}

\author{
M. M. Cabling ${ }^{\text {, }, ~ H . ~ S . ~ K a n g ~}{ }^{\text {a }}$, B. M. Lopez, M. Jang, H. S. Kim, K. C. Nam, J. G. Choi ${ }^{1}$, and K. S. Seo* \\ Department of Animal Science and Technology, Sunchon National University, Suncheon 540-742, Korea
}

\begin{abstract}
Data collected from 690 purebred Duroc pigs from 2009 to 2012 were used to estimate the heritability, and genetic and phenotypic correlations between production and meat quality traits. Variance components were obtained through the restricted maximum likelihood procedure using Wombat and SAS version 9.0. Animals were raised under the same management in five different breeding farms. The average daily gain, loin muscle area (LMA), backfat thickness (BF), and lean percent (LP) were measured as production traits. Meat quality traits included $\mathrm{pH}$, cooking loss, lightness $\left(\mathrm{L}^{*}\right)$, redness $\left(\mathrm{a}^{*}\right)$, yellowness $\left(\mathrm{b}^{*}\right)$, marbling score (MS), moisture content (MC), water holding capacity (WHC), and shear force. The results showed that the heritability estimates for meat quality traits varied largely from 0.19 to 0.79 . Production traits were moderate to highly heritable from 0.41 to 0.73 . Genotypically, the BF was positively correlated $(\mathrm{p}<0.05)$ with $\mathrm{MC}(0.786)$, WHC $(0.904)$, and $\mathrm{pH}(0.328)$ but negatively correlated with shear force $(-0.533)$. The results of genetic correlations indicated that selection for less $\mathrm{BF}$ could decrease $\mathrm{pH}$, moisture content, and WHC and increase the shear force of meat. Additionally, a significant positive correlation was recorded between average daily gain and WHC, which indicates pork from faster-growing animals has higher WHC. Furthermore, selection for larger LMA and LP could increase MS and lightness color of meat. The meat quality and production traits could be improved simultaneously if desired. Hence, to avoid further deterioration of pork characteristics, appropriate selection of traits should be considered. (Key Words: Genetic Parameters, Production Traits, Meat Quality Traits, Duroc)
\end{abstract}

\section{INTRODUCTION}

The swine industry plays a very important role in the animal industry as it accounts for $42 \%$ of the total animal production (RDA report, 2011). Consumer demand is rapidly increasing, necessitating that genetic potential be maximized and overall farm management improved. Additionally, improvements in production have the potential to boost exports to neighboring countries. Improvements of animal performance to their highest

\footnotetext{
* Corresponding Author: K. S. Seo. Tel: +82-61-750-3231, Fax: +82-61-750- 3230, E-mail: sks@ sunchon.ac.kr

${ }^{1}$ Animal Breeding and Genetics Division, National Institute of Animal Science, Rural Development Administration, Suncheon 540-950, Korea.

${ }^{a}$ Meriam M. Cabling and Hyunsung Kang contributed equally to this study.

Submitted Oct. 8, 2014; Revised Nov. 26, 2014; Accepted Feb. 13, 2015
}

genetic potential have been made possible through modern technology and knowledge. Such improvements focus on growth and production efficiency, carcass yield and meat quality. Many of these traits are moderately to highly heritable, and the response to selection is highly dependent on variations in the population and selection intensity (Falconer, 1989; Dube et al., 2013). The response to selection is influenced by correlations among traits that could be desirable or undesirable (Miar et al., 2014). Therefore, heritability and correlation between production traits and meat quality traits should be considered during selection.

This study was conducted to determine the relationship between production traits and meat quality traits of purebred Duroc pigs. Specifically, heritability and the phenotypic and genetic correlations between traits were estimated. The results of this study will lead to improved selection of traits that are economically important. 


\section{MATERIALS AND METHODS}

\section{Experimental animals}

Data for this study were obtained from 690 finishing Duroc pigs over 4 years (2009 through 2012). The data were combined from five different breeding farms under national genetic improvement project. The animals were composed of 633 females and 57 males raised under the same management conditions. Piglets were delivered to different farms at approximately 10 to 20 days of age and raised under commercial finishing conditions. A standard health and vaccination protocol was implemented. All pigs were raised in a adjusted open-front finisher with a partially slotted floor and given $1.4 \mathrm{~m}^{2}$ of pen space per pig.

\section{Performance measurement}

Performance data were collected when the animals reached 9 to 22 weeks of age. The average daily gain (ADG) was obtained from the difference between final weight and initial weight divided by the days fed. Lean meat percentage (LP) was acquired by determining the percentage weight of the whole carcass. The loin muscle area (LMA) was measured between the third and fourth ribs 3 inches away from the midline using an A-mode ultrasound device (PIGLOG 105), then calculated using the following equation:

$$
\begin{aligned}
& \text { LMA }=\text { loin muscle measurement } \\
& +\frac{(90-\text { test end weight }) \times \text { loin muscle measurements }}{(\text { test end weight }+70.31)}
\end{aligned}
$$

The backfat thickness (BF) was measured on all live animals ultrasonically at the tenth rib $4 \mathrm{~cm}$ from the midline and adjusted to $90 \mathrm{~kg}$ using the formula below:

$$
\begin{aligned}
& \mathrm{BF}=\text { backfat measurement } \\
& +\frac{(90-\text { test end weight }) \times \text { backfat measurements }}{(\text { test end weight }-11.34)}
\end{aligned}
$$

\section{Meat quality measurements}

The samples were collected from two different slaughterhouses, where different farms were instructed to bring the animals after they reached the target end weight of $120 \mathrm{~kg}$ for carcass evaluation, and then carried to the laboratory immediately for meat quality measurement. The $\mathrm{pH}$ value of meat was measured using an Orion 3 Star (Thermo Electron Corp., Waltham, MA, USA) pH meter in the loin muscle at 2 locations at $24 \mathrm{~h}$ postmortem. Shear value and cooking loss (CL) were determined on the same sample block after thawing overnight in a chiller. The samples were weighed and cooked at $72^{\circ} \mathrm{C}$, after which the CL was determined by dividing the weight loss after cooking by the weight of the sample before cooking. Shear values were measured in an Instron Universal Testing Machine (Model 3342, Instron Corporation, Norwood, MA, USA) on six core samples with a 0.5 inch diameter using a crosshead speed of $400 \mathrm{~mm} / \mathrm{min}$ and a $40 \mathrm{~kg} / \mathrm{f}$ load cell. The moisture content (MC) was obtained through a slightly modified method of the AOAC methods (AOAC, 1995). The water holding capacity (WHC) was determined after the ground meat was centrifuged at $1,000 \mathrm{rpm}$ for 10 minutes at $4^{\circ} \mathrm{C}$ and measured using absorbent cotton placed inside of a Falcon tube. The meat colors, lightness $\left(\mathrm{L}^{*}\right)$, redness $\left(a^{*}\right)$ and yellowness $\left(b^{*}\right)$ were measured after cutting and blooming for more than 15 min using a Konica Minolta Spectrophotometer CM-2500d with an $8 \mathrm{~mm}$ measuring port, D 65 illuminant and $10^{\circ}$ observer. The tristimulus parameters $\mathrm{L}^{*}, \mathrm{a}^{*}$, and $\mathrm{b}^{*}$ values, representing lightness $\left(\mathrm{L}^{*}=0\right.$ is completely black, and $\mathrm{L}^{*}=100$ is completely white), redness (positive $\mathrm{a}^{*}$ values mean red colors and negative $a^{*}$ values mean green colors) and yellowness (positive $b^{*}$ values mean yellow colors and negative $b^{*}$ values mean blue colors), respectively, were measured in duplicate on three fixed sites of each chop surface of the loin, in the dorsal ventral direction. Minolta instrument was directly connected to a computer, and a barcode scanner gave a fast and accurate measurement.

\section{Statistical analyses}

The general linear model (GLM) procedure of the Statistical Analysis Systems Institute (SAS, 2002) was used to test the significance of fixed effects, covariates and any possible interactions among factors. Pearson correlation coefficients between traits were calculated using the PROC CORR procedure. Variance-covariance components and standard error were obtained through the Restricted Maximum Likelihood procedures of WOMBAT and SAS program version 9.0. The model used accounted for random direct genetic, common environmental litter and maternal genetic effects. In matrix form, the model is:

$$
\mathbf{y}_{i j k}=\boldsymbol{\mu}+\mathbf{f}_{i}+\mathbf{S}_{j}+(\text { Day }) \boldsymbol{\beta}_{i j k}+\mathbf{e}_{i j k}
$$

where $Y_{i j k}$ is the vector of observations of the traits, $\mu$ is the overall mean, $f_{i}$ is the ith farm effect, $S_{j}$ is the jth sex effect, $\beta$ is the regression coefficient of slaughter day (Day), $\mathrm{e}_{\mathrm{ijk}}$ is the random error. All fixed factors included in the model were significant ( $p>0.05$ ) based on the GLM analysis. Heritability was calculated as the ratio of animal genetic variance to the sum of additive genetic, common environment, and residual variances. Three generations of pedigree information comprising 5,869 animals from January 2007 to June 2012 were included in the analysis. Genetic and phenotypic correlations were estimated using a multi-trait model. All traits were analyzed together in one 
model.

\section{RESULTS AND DISCUSSION}

Descriptive statistics for production and meat quality traits are presented in Table 1. The mean ADG, BF, LMA and $\mathrm{LP}$ were $640.41 \mathrm{~g} / \mathrm{d}, 14.61 \mathrm{~mm}, 28.25 \mathrm{~cm}^{2}$ and $55.89 \%$, respectively. For meat quality traits, the average $\mathrm{pH}, \mathrm{CL}$, marbling score (MS), MC, shear force, and WHC were 5.74, $22.45 \%, 3.72,72.72 \%, 4.40$, and 54.93 , respectively. In meat colors, the mean $\mathrm{L}^{*}, \mathrm{a}^{*}$, and $\mathrm{b}^{*}$ were $54.67,9.76$, and 9.82 , respectively.

\section{Heritability}

The heritability estimates with standard error for some production traits are presented in Table 2. Production traits such as ADG, BF, LMA, and LP were highly heritable. Heritability estimates with standard error for ADG, BF, LMA, and LP were $0.67 \pm 0.06,0.65 \pm 0.06,0.41 \pm 0.05$, and $0.73 \pm 0.08$, respectively. These estimates are higher, except LMA, in the review study conducted by Akanno et al. (2013), where heritability estimates for the same traits were ranging from 0.24 to $0.32,0.36$ to $0.52,0.37$ to 0.65 , and 0.35 to 0.49 , respectively. Stewart and Shinckel (1990) used a weighted average of results reported in studies from the United States and Europe and found a heritability of 0.47 for LMA, which is similar to the results of the present study (0.41). Other estimates of heritability of backfat in the literature ranged from 0.23 to 0.79 (Van Steenbergen et al., 1990). Lo et al. (1992) reported that the heritability estimate for ADG data from a $2 \times 2$ parallel mating system of Landrace and Duroc pigs was 0.36, which is lower than the $0.67 \pm 0.06$ observed in the present study.

Table 2 presents the heritability estimates and standard

Table 1. Summary of production and meat quality traits

\begin{tabular}{lccccc}
\hline Trait & $\mathrm{N}$ & Min & Max & Mean & SD \\
\hline ADG $(\mathrm{g} / \mathrm{d})$ & 616 & 488.00 & 828.80 & 640.41 & 57.64 \\
$\mathrm{BF}(\mathrm{mm})$ & 616 & 8.61 & 24.23 & 14.61 & 2.66 \\
LMA $\left(\mathrm{cm}^{2}\right)$ & 554 & 19.72 & 38.78 & 28.25 & 3.21 \\
LP $(\%)$ & 554 & 44.00 & 65.90 & 55.89 & 3.49 \\
$\mathrm{pH}$ & 598 & 5.44 & 6.49 & 5.74 & 0.15 \\
MC $(\%)$ & 593 & 63.20 & 79.33 & 72.72 & 2.25 \\
WHC & 597 & 10.44 & 88.72 & 54.93 & 21.93 \\
CL $(\%)$ & 597 & 6.65 & 42.60 & 22.45 & 6.68 \\
MS & 574 & 0.59 & 14.02 & 3.72 & 1.64 \\
L* & 608 & 41.23 & 66.95 & 54.67 & 4.14 \\
a* & 608 & 2.08 & 20.61 & 9.76 & 4.87 \\
b* & 608 & 3.65 & 17.67 & 9.82 & 2.71 \\
Shear force & 597 & 1.25 & 8.80 & 4.40 & 1.66 \\
\hline
\end{tabular}

SD, standard deviation; ADG, average daily gain; BF, backfat thickness; LMA, longissimus muscle area; LP, lean percent; MC, moisture content; WHC, water holding capacity; CL, cooking loss; MS, marbling score; $\mathrm{L}^{*}$,lightness, $\mathrm{a}^{*}$, redness, $\mathrm{b}^{*}$, yellowness.
Table 2. Estimates of total genetic and environmental variances, heritability and standard error for production and meat quality traits in Duroc pigs

\begin{tabular}{lcccc}
\hline Trait & $\begin{array}{c}\text { Total } \\
\text { genetic } \\
\text { variance }\end{array}$ & $\begin{array}{c}\text { Environmental } \\
\text { variance }\end{array}$ & Heritability & SE \\
\hline ADG & 508.7 & 254.82 & 0.67 & 0.06 \\
BF & 3.678 & 1.953 & 0.65 & 0.06 \\
LMA & 3.508 & 4.96 & 0.41 & 0.05 \\
LP & 6.06 & 2.24 & 0.73 & 0.08 \\
pH & 0.0129 & 0.008 & 0.61 & 0.08 \\
MC & 0.906 & 2.471 & 0.27 & 0.06 \\
WHC & 5.558 & 23.37 & 0.19 & 0.06 \\
CL & 9.981 & 6.211 & 0.62 & 0.07 \\
MS & 1.694 & 0.463 & 0.79 & 0.08 \\
L* & 4.945 & 6.264 & 0.44 & 0.08 \\
a* & 2.595 & 1.233 & 0.68 & 0.08 \\
b* & 2.532 & 1.420 & 0.64 & 0.05 \\
Shear force & 0.066 & 1.578 & 0.04 & 0.05 \\
\hline SE, stard & &
\end{tabular}

SE, standard error; ADG, average daily gain; BF, backfat thickness; LMA, longissimus muscle area; LP, lean percent; MC, moisture content; WHC, water holding capacity; CL, cooking loss; MS, marbling score; $\mathrm{L}^{*}$, lightness; $\mathrm{a}^{*}$, redness; $\mathrm{b}^{*}$, yellowness.

error for meat quality traits, which varied largely from 0.19 to 0.79. In a study conducted by Lo et al. (1992), heritability estimates for $\mathrm{pH}, \mathrm{MC}, \mathrm{WHC}, \mathrm{CL}, \mathrm{MS}$, and shear force were $0.14,0.14,0.25,0.06,0.17$, and 0.17 , respectively. These values were comparatively lower than those reported in the present study, particularly for the $\mathrm{pH}$ $(0.61 \pm 0.08)$, marbling score $(0.79 \pm 0.08)$, and CL $(0.62 \pm 0.07)$. A number of studies (e.g. Wilson and Johnson, 1981; Lowe et al., 2011) showed that Duroc breed had a high amount of marbling and more rapid growth than Hampshire and Yorkshire breeds. Ciobanu et al. (2011) reported an average heritability value of 0.16 for CL. In comparison, high common environmental effects were also shown in this study for CL (0.62). Cameron (1990b) reported a heritability of 0.20 for muscle $\mathrm{pH}$ at 24 hour postmortem. This study revealed that $\mathrm{pH}$ was highly heritable in purebred Duroc pigs, which are considered one of the most important traits in meat quality. Furtheremore, this study also obtained a higher heritability estimate for lightness, which was 0.44 with standard error of 0.08 . Suzuki et al. (2006) reported that the heritability estimates for meat color $\left(L^{*}\right)$ was 0.16 while Hermesh et al. (1993a) reported an estimate of 0.29 .

\section{Genetic correlations}

The genetic correlations between production and meat quality traits are presented in Table 3. Generally, some of the correlations were significant $(\mathrm{p}<0.05)$. Genetic correlations estimated in the current investigation support the general impression that selection for increased backfat 
Table 3. Phenotypic and genetic correlations between production and meat quality traits

\begin{tabular}{|c|c|c|c|c|c|c|c|c|}
\hline \multirow{2}{*}{ Traits } & \multicolumn{2}{|c|}{ ADG } & \multicolumn{2}{|c|}{$\mathrm{BF}$} & \multicolumn{2}{|c|}{ LMA } & \multicolumn{2}{|c|}{ LP } \\
\hline & $r_{P}$ & $r_{G}$ & $r_{P}$ & $r_{G}$ & $r_{P}$ & $r_{G}$ & $r_{P}$ & $r_{G}$ \\
\hline$\overline{\mathrm{pH}}$ & -0.06 & -0.004 & -0.07 & 0.328 & 0.12 & -0.226 & 0.07 & -0.104 \\
\hline $\mathrm{MC}$ & -0.10 & -0.010 & 0.02 & 0.786 & 0.00 & 0.038 & -0.22 & -0.342 \\
\hline WHC & 0.14 & 0.875 & 0.06 & 0.904 & -0.16 & 0.002 & -0.02 & -0.504 \\
\hline $\mathrm{CL}$ & 0.00 & 0.185 & -0.05 & 0.206 & 0.17 & 0.044 & 0.15 & -0.072 \\
\hline MS & 0.02 & 0.011 & 0.04 & -0.414 & -0.18 & 0.307 & -0.22 & 0.307 \\
\hline $\mathrm{L}^{*}$ & 0.08 & 0.025 & 0.13 & -0.173 & -0.10 & 0.325 & -0.32 & 0.248 \\
\hline$a^{*}$ & -0.02 & -0.053 & 0.17 & 0.455 & -0.13 & 0.236 & -0.24 & -0.027 \\
\hline$b^{*}$ & -0.06 & -0.084 & -0.17 & -0.240 & 0.18 & 0.187 & 0.29 & 0.265 \\
\hline Shear force & 0.01 & 0.478 & -0.21 & -0.533 & 0.05 & 0.516 & 0.18 & 0.503 \\
\hline
\end{tabular}

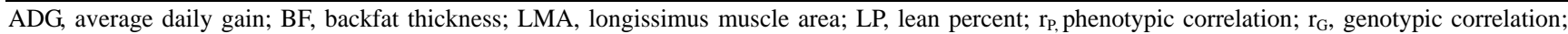
MC, moisture content; WHC, water holding capacity; CL, cooking loss; MS, marbling score; L*, lightness; $a^{*}$, redness; $b^{*}$, Yellowness.

should lead to a correlated increase in MC and WHC. In this study, the BF was positively correlated with $\mathrm{MC}$ (0.786), WHC (0.904) and a* (0.455). According to Suzuki et al. (2005), as the intramuscular fat content increases, the WHC will also increase. Moreover, WHC was strong positively correlated with ADG (0.875). These findings showed that pork from faster-growing pigs has higher WHC. The MS was positively correlated with LP (0.307) and negatively correlated with BF $(-0.414)$. These results showed that meat from leaned and less backfat animals had better MS. The shear force was positively correlated with ADG (0.478), LMA (0.516) and LP (0.503) but negatively correlated with BF $(-0.533)$. These results showed that when selection favors production traits such as ADG, BF, LMA, and LP, it will favored the shear force of meat, which is a good indication of meat tenderness. These findings contrast the result reported by Suzuki et al. (2005), who found that tenderness was negatively correlated with ADG $(-0.44)$.

\section{Phenotypic correlations}

Phenotypic correlations between production and meat quality traits varied greatly (Table 3 ). Hermesch et al. (2000b) reported that production traits were genetically independent from meat quality traits, while selection for improved feed efficiency and increased leanness will increase the incidence of pale, soft, and exudative (PSE) meat and reduce intramuscular fat. These results are similar to those of the present study. The $\mathrm{pH}$ of meat, which served as a significant source of variations in meat quality (Price and Schweigert, 1987), showed a positive correlation with LMA (0.12), but showed no significant correlation with other production traits. Bidanel et al. (1994) reported that selection for reduced backfat could reduce $\mathrm{pH}$, and thus increased the incidence of PSE meat.

The WHC showed a negative correlation with LMA $(-0.16)$ and positive correlation with ADG (0.14). This correlation between WHC and ADG showed that pork from fast-growing pigs has phenotypically higher WHC. Berg et al. (2003) investigated several breeds and found higher values of WHC, intramuscular fat, content and ultimate $\mathrm{pH}$, as well as lower lightness in the longissimus dorsi muscle for Duroc pig compared to Landrace. The marbling score, lightness, and redness were negatively correlated with LP and LMA. This moderate negative correlation $(-0.22)$ between MS and LP showed that leaned pigs do not show high marbling score phenotypically. The lightness and redness traits were positively correlated with $\mathrm{BF}$, which was in contrast to the yellowness trait.

Moreover, shear force was positively correlated with LP (0.18), but negatively correlated with BF $(-0.21)$. This could be explained by the amount of intramuscular fat content. It is well known that shear force is an important index for evaluation of the tenderness of pork. The shear force decreases with increasing intramuscular fat content when the $\mathrm{pH}$ increases above 4.5 (Jelenikova et al., 2008). Correlations were found between shear force (tenderness) and intramuscular fat content. Similarly, a positive relationship was observed between shear force and $\mathrm{pH}$ value at 4.5 minutes $(\mathrm{pH} 4.5)$ post mortem.

\section{IMPLICATIONS}

The present study revealed that there were desirable and undesirable correlations between production and meat quality traits of Duroc pigs. The $\mathrm{pH}$ was associated with high heritability estimates, although it had unfavorable genetic correlations with LMA and LP, and an insignificant relationship with ADG. In addition, the observed genetic correlations broadly indicate that selection for less BF could lower $\mathrm{pH}, \mathrm{MC}$, and WHC. Moreover, selection for larger LMA and LP could increase marbling score and lightness color of meat, genotypically, but LP was phenotypically negatively correlated with MS. This results showed that LP and MS has desirable genetic correlation but does not appear physically. Therefore, it was suggest for more deep 
study in this correlation. A significant positive genetic correlation of WHC with ADG and BF, and negative genetic correlation with LP were also recorded in this study. These findings imply that meat quality and production traits could be improved simultaneously if desired. Therefore, appropriate traits should be selected to avoid further deterioration of pork characteristics.

\section{ACKNOWLEDGMENTS}

This research was supported by Golden Seed Project, Ministry of Agriculture, Food and Rural Affairs (MAFRA), Ministry of Oceans and Fisheries (MOF), Rural Development Administration (RDA) and Korea Forest Service (KFS) (project no. PJ009922).

\section{REFERENCES}

AOAC. 1995. Official Methods of Analysis Association of Official Analytical Chemist. 16th Ed, Washington, DC, USA.

Akkanno, E. C., F. S. Schenkel, V. M. Quinton, R. M. Friendship, and J. A. B. Robinson. 2013. Meta-analysis of genetic parameter estimates for reproduction, growth and carcass traits of pigs in the tropics. Livest. Sci. 152:101-113.

Berg, E. P., E. L. McFadin, R. R. Maddock, N. Goodwin, T. J. Baas, and D. H. Keisler. 2003. Serum concentrations of leptin in six genetic lines of swine and relationship with growth and carcass characteristics. J. Anim. Sci. 81:167-171.

Bidanel, J. P., A. Ducos, F. Labroue, R. Gueblez, and C. Gasnier. 1994. Genetic parameters of backfat thickness, age at $100 \mathrm{~kg}$ and meat quality raits in Pietrain pigs. Ann. Zootech. 43:141149.

Cameron, N. D. 1990. Genetic and phenotypic parameters for carcass traits, meat and eating quality traits in pigs. Livest. Prod. Sci. 26:119-135.

Ciobanu, D., S. M. Lonergan, and E. J. Huff-Lonergan. 2011. Gtenetics of meat quality and carcass traits. In: The genetics of the pigs (Eds. M. F. Rothschild and A. Rubinsky). CAB Int., New York, NY, USA. 355-389.

Dube, B., S. D. Mulugeta, and K. Dzama. 2013. Genetic relationship between growth and carcass traits in Large white pigs. S. Afr. J. Anim. Sci. 43:482-491.

Falconer, D. S. 1989. Introduction to Quantitative Genetics. 3rd ed. John Wiley and Sons Inc., New York, NY, USA.
Hermesch, S., B. G. Luxford, and H.-U. Graser. 2000b. Genetic parameters for lean meat yield, meat quality, reproduction and feed efficiency traits for Australian pigs: 2. Genetic relationship between production, carcass and meat quality traits. Livest. Prod. Sci. 65:249-259.

Jeleníková J., P. Pipek, and M. Miyahara. 2008. The effects of breed, sex, intramuscular fat and ultimate $\mathrm{pH}$ on pork tenderness. Eur. Food Res. Technol. 227:989-994.

Johnson Z. B., J. J. Chewning, and R. A. Nugent III. 1999. Genetic parameters for production traits and measures of residual feed intake in large white swine. J. Anim. Sci. 77:1679-1685.

Lowe, B. K., D. L. Clark, D. D. Boler, A. C. Dilger, F. K. McKeith, J. M. Eggert, D. W. Newcom, and J. Killefer. 2011. Characterization of Loin shape from Duroc and Duroc composite finishing gilts. Meat Sci. 87:146-150.

Miar Y., G. S. Plastow, S. S. Moore, G. Manafiazar, P. Charagu, R. A. Kemp, B. Van Haandel, A. E. Huisman, C. Y. Zhang, R. M. McKay, H. L. Bruce, and Z. Wang. 2014. Genetic and phenotypic parameters for carcass and meat quality traits in commercial crossbred pigs. J. Anim. Sci. 92:2869-2884.

Price, J. F. and B. S. Schweigert. 1987. The Science of Meat and Meat Products. 3rd Ed. Food \& Nutrition Press, Trumbull, CT, USA.

SAS Institute Inc. 2002. SAS/STAT User Guide, Release 8.0, Cary, NC, USA.

Stewart, T. S. and A. P. Schinckel. 1990. Genetic parameters for swine growth and carcass traits. In: Genetics of Swine (Ed. L. D. Young). North Central Reg. Pub., USDA, Clay Center, NE, USA.

Suzuki K., M. Ishida, H. Kadowak, T. Shibata, H. Uchida, and A. Nishida. 2006. Genetic correlations among fatty acid compositions in different sites of fat tissues, meat production, and meat quality traits in Duroc pigs. J. Anim. Sci. 84:20262034.

Suzuki. K., M. Irie, H. Kadowaki, T. Shibata, M. Kumagai, and A. Nishida. 2005. Genetic parameter estimates of meat quality traits in Duroc pigs selected for average daily gain, longissimus muscle area, backfat thickness, and intramuscular fat content. J. Anim. Sci. 83:2058-2065.

Van Steenbergen, E. J., E. Kanis, and H. A. M. Van Der Steen. 1990. Genetic parameters of fattening performance and exterior traits of boars tested in central stations. Livest. Prod. Sci. 24:65-82.

Wilson, E. R. and R. K. Johnson. 1981. Comparison of three-breed and backcross swine for litter productivity and postweaning performance. J. Anim. Sci. 52:18-25. 